\title{
Discovery of Two Historical Computers in Switzerland: Zuse Machine M9 and Contraves Cora and Discovery of Unknown Documents on the Early History of Computing at the ETH Archives
}

\author{
Herbert Bruderer \\ Swiss Federal Institute of Technology, Zurich \\ herbert.bruderer@inf.ethz.ch, herbert.bruderer@bluewin.ch
}

\begin{abstract}
Since 2009 we have been trying to find out more about the beginnings of computer science in Switzerland and abroad. Most eyewitnesses have already died or are over 80 years old. In general, early analog and digital computers have been dismantled long ago. Subject to exceptions, the few remaining devices are no longer functioning. Many documents have gone lost. Therefore investigations are difficult and very time-consuming. However, we were able to discover several unknown historical computers and hundreds of exciting documents of the 1950s. In 2012, the results have been published in a first book; a second volume will be forthcoming next year.
\end{abstract}

Keywords: Cora, ERMETH, ETH archives, Hasler AG, Heinz Rutishauser, Konrad Zuse, M9 (=Z9), Mithra AG, Paillard SA, Remington Rand AG, Unesco, Z4.

\section{Introduction}

My investigations into the history of computing started in 2009 in connection with the Zuse centenary $\left(100^{\text {th }}\right.$ birthday of the German computer pioneer in 2010). The goal was to get a more comprehensive and deeper understanding of the events of the pioneering days. Coincidentally and to our surprise we discovered the programcontrolled Zuse relay calculator M9 whose existence was unknown even to computer scientists. Shortly afterwards another machine emerged: the Swiss made transistor computer Cora. From 2010 to 2013 several contemporary eyewitness discussions concerning M9 and Cora took place. In addition to the oral history we attempted to find objects which may have been conserved. To our knowledge, in both cases only a single machine has survived. For the first time, the ETH archives in Zurich were systematically examined with regard to the early history of computing. We soon became aware of their rich cultural heritage. The archives are indeed a true treasure for the history of technology. Research is still ongoing. 


\section{Discovery of Historical Computers}

\subsection{0: Discovery of the Zuse Machine M9 (=Z9)}

The M9 was the first program-controlled Zuse machine manufactured in series (25-30 copies). Remington Rand AG, Zurich, initiated the design and construction of the M9 by Zuse KG. M9 is equal to Z9. The name derives from Mithra AG, a Zurich based subsidiary of Remington Rand. It was chosen in order to avoid patent contests. In 2011, we found unique photographs and drawings of the M9 in the Swiss mountain valley of Toggenburg. These are the only existing high-quality pictures of the Zuse calculating punch. To our knowledge, a single copy of an M9 has been preserved. It is now at the main repository of the Museum für Kommunikation in Berne. The machine had been used by the government of the city of Winterthur. We conducted a video interview (DVD) with three eyewitnesses (technical staff) of the M9.

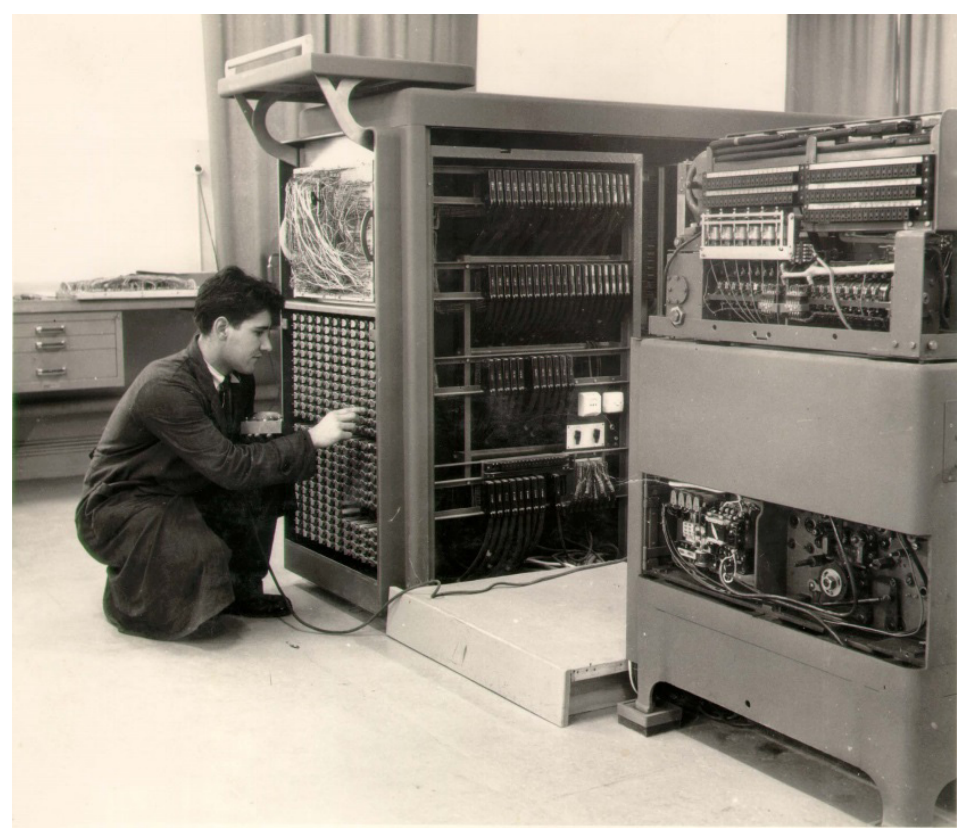

Fig. 1. The program-controlled decimal Zuse relay calculator M9 (=Z9) at Dietfurt (Switzerland), (C) Max Forrer, Oberhelfenschwil

\subsection{1: Discovery of the Contraves Computer Cora 1}

Cora is the first Swiss transistor computer, designed and built by Contraves AG, Zurich. Chief engineer was Peter Toth from Hungary. Cora was operational in 1963 and controlled a high-precision plotter called Coragraph. It was demonstrated at the Swiss national exhibition in Lausanne in 1964. The plotter produced technical drawings such as the outline of the castle of Thun, however the computer was hidden 
behind a wall. The system was sold throughout the world. As far as we know, only one copy of the Cora 1 is still alive. It can be seen at the Bolo museum of the Swiss Federal Institute of Technology, Lausanne. The Swiss engineer Peter Blum was responsible for the Cora 2 which was available in 1969. The machine was primarily developed for military applications. Contraves also wrote a Fortran compiler.

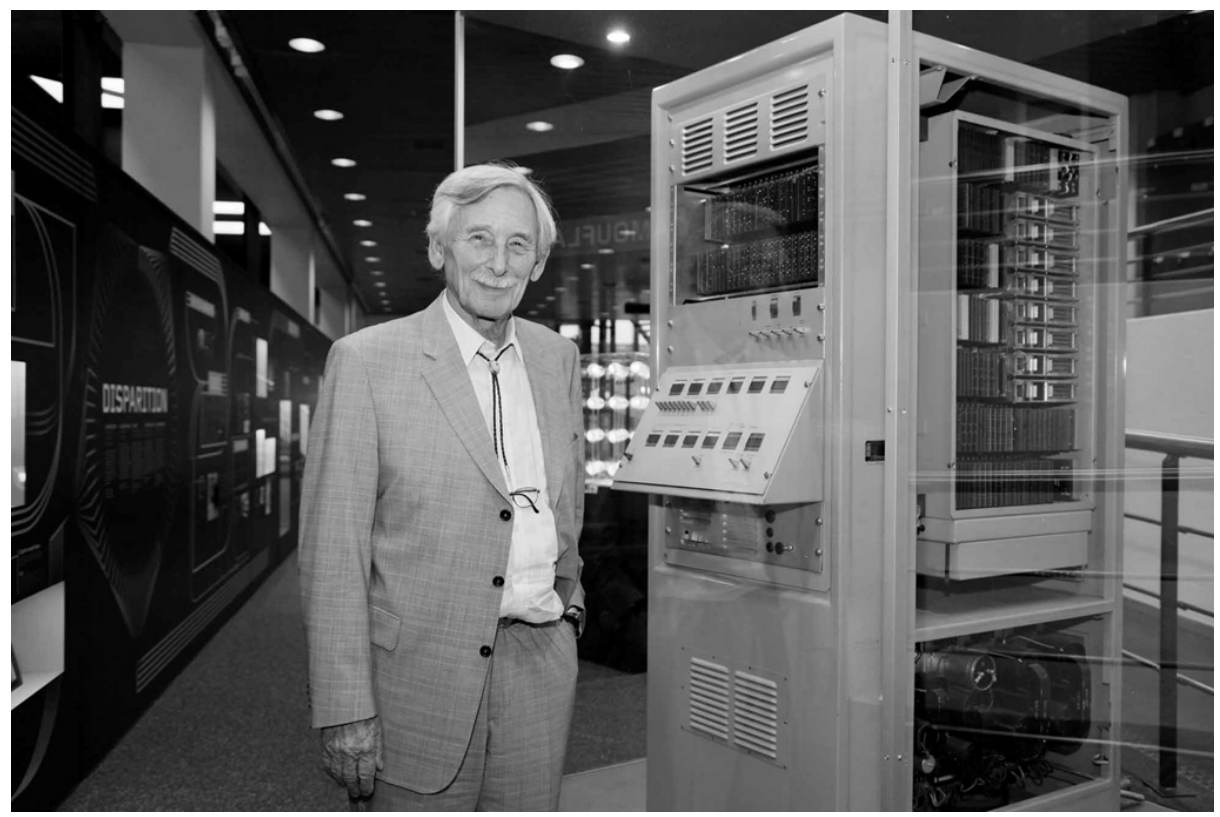

Fig. 2. The first Swiss transistor computer Cora 1 and its Hungarian designer Peter Toth, CMusée Bolo, EPFL Lausanne

\section{Discovery of Historical Documents}

\subsection{1 to 2013: Discovery of Unknown Documents on the Early History of Computing}

We found very interesting documents in the archives of the Swiss Federal Institute of Technology, Zurich (ETH Zurich). Other findings relate to the Museum für Kommunikation. The documents mostly refer to the electromechanical digital Z4 and the electronic digital ERMETH. These letters, contracts, reports, and papers necessitate a (at least partial) rewriting of the early history of computing in Switzerland and elsewhere.

\subsection{Zuse Machine Z4}

In 1950, ETH was the only university in Continental Europe with a functioning computer. Zuse's digital relay calculator Z4 was in operation in Zurich from 1950 to 


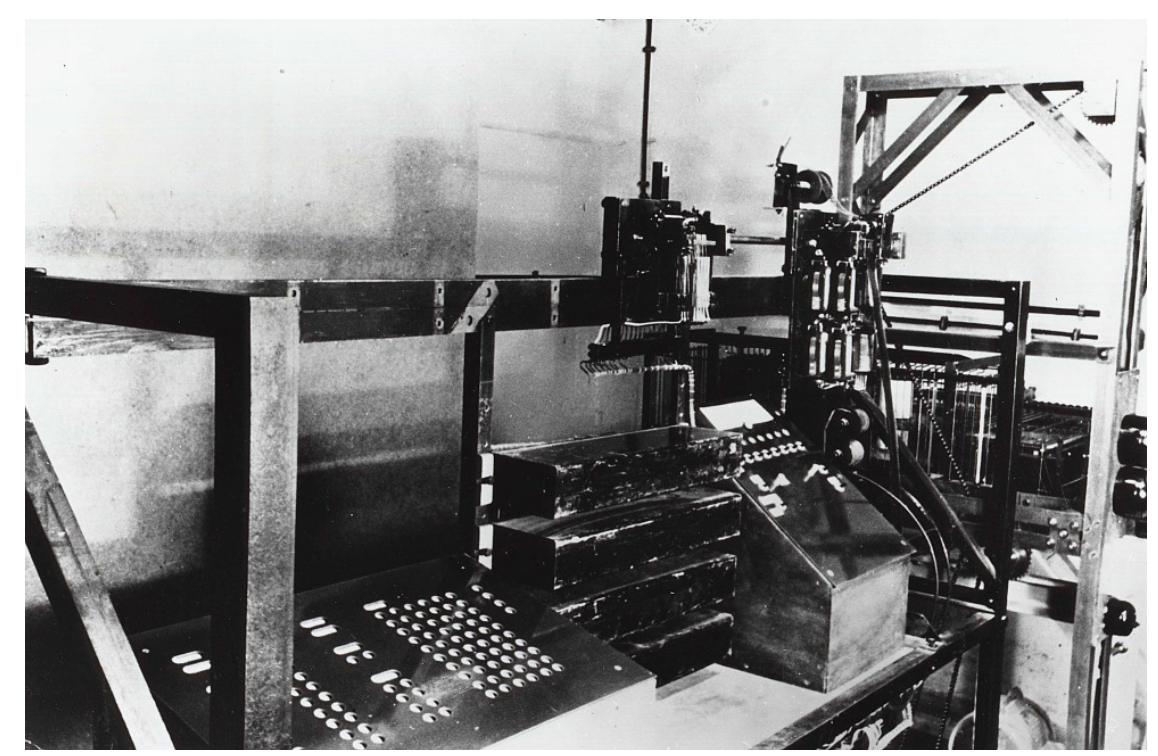

Fig. 3. The Zuse machine Z4 (with floating-point arithmetic) at Hopferau (Bavaria) was in a bad condition (1949), (C) ETH Zurich, Bildarchiv

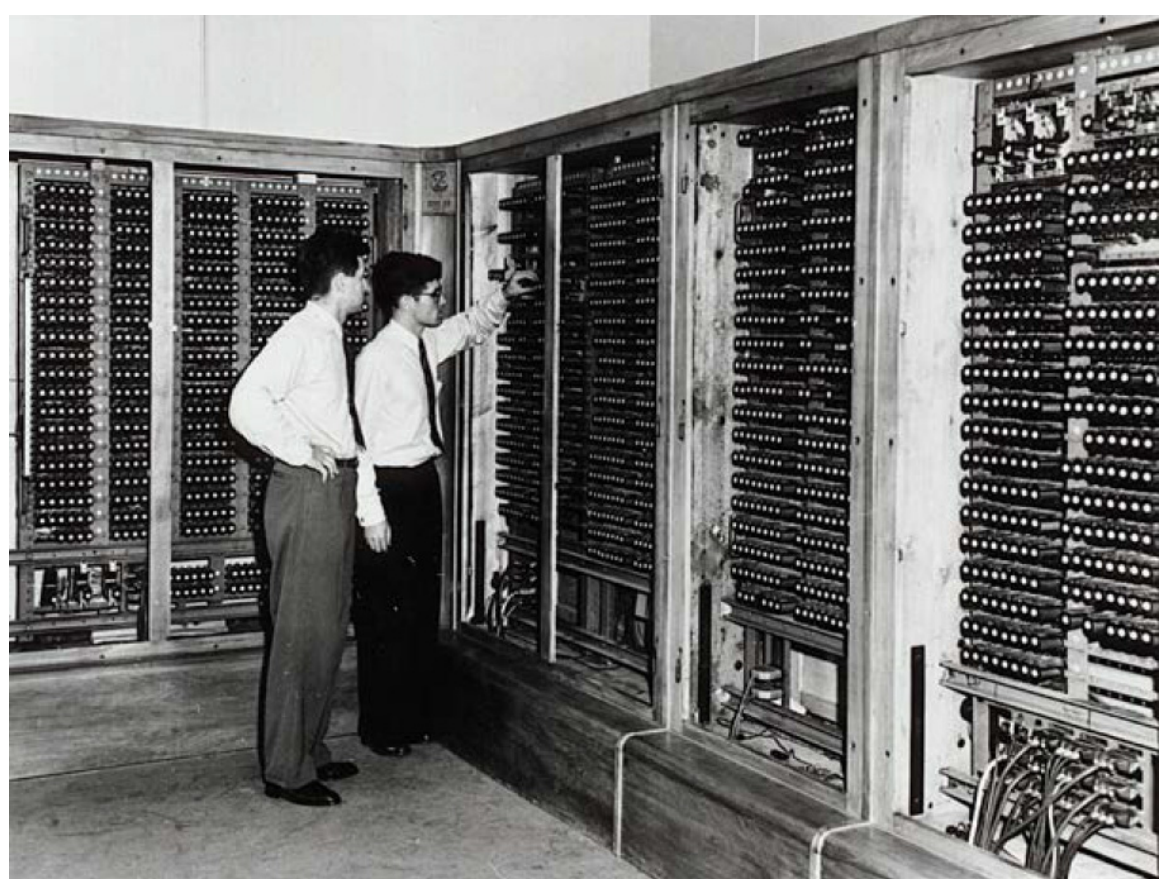

Fig. 4. The program-controlled binary Zuse relay calculator Z4 in operation at the ETH Zurich (1950-1955), (C) ETH Zurich, Bildarchiv 


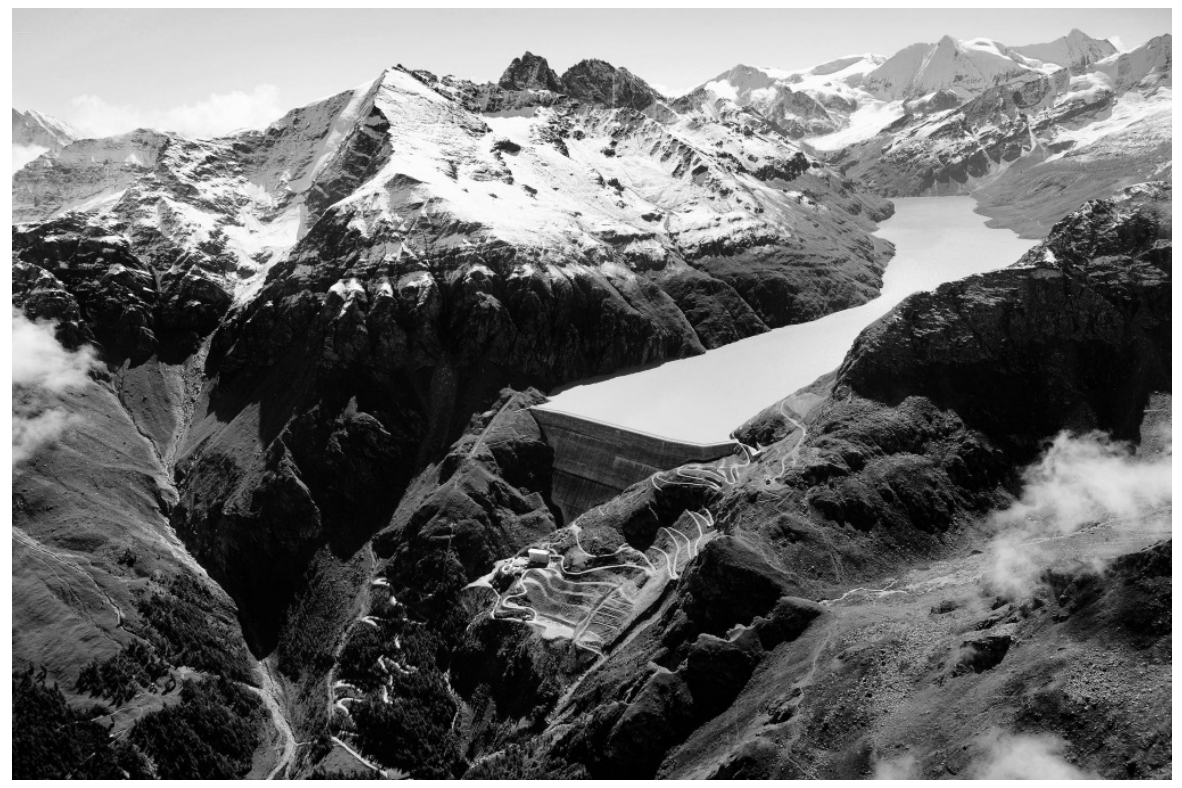

Fig. 5. The world's highest massive dam (Swiss Alps). The $\mathrm{Z} 4$ calculated the tensions, (C)Grande Dixence SA/essencedesgin.com

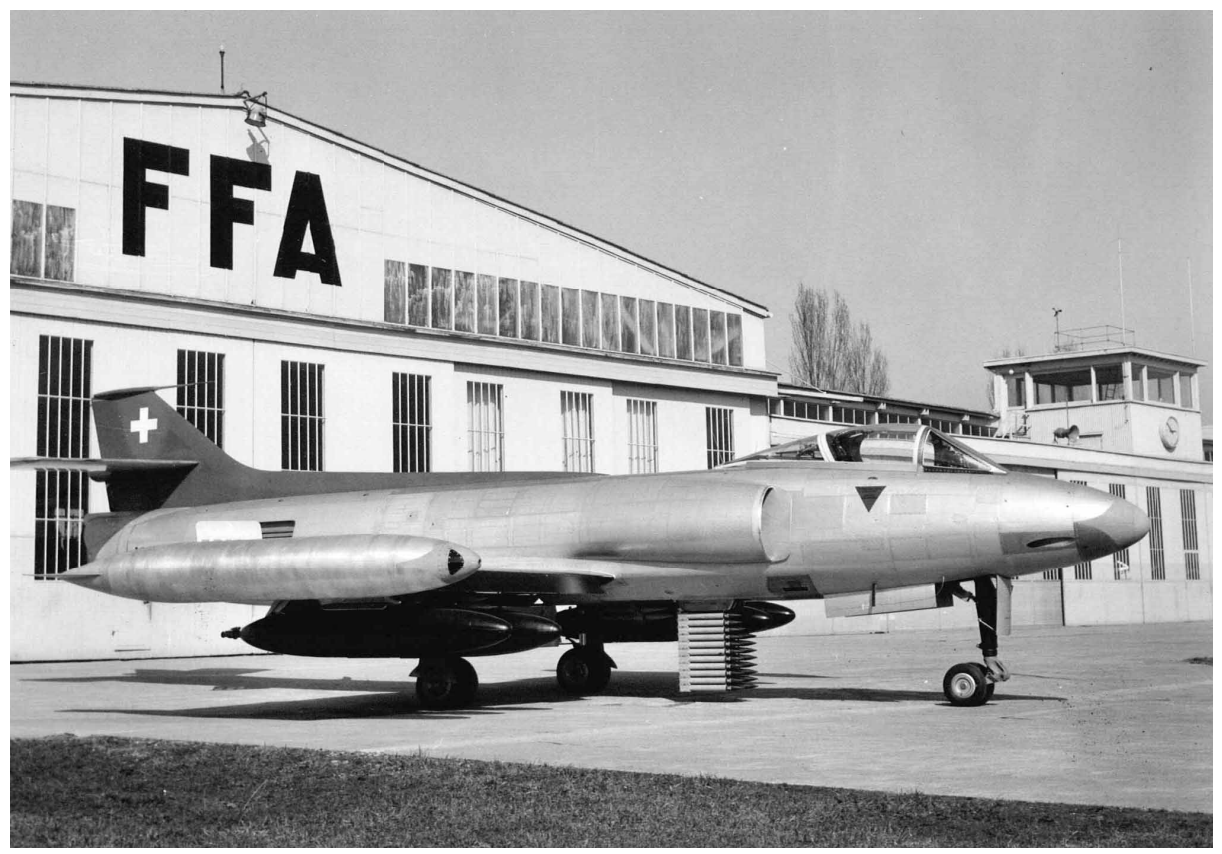

Fig. 6. The Swiss jet fighter P-16 on Lake Constance. The Z4 was used for the flutter calculations, (C) Staatsarchiv, St. Gallen 
1955. ETH had rented the machine. In many respects, Z4 was more modern than its American counterparts because it was a program-controlled binary device using floating-point arithmetic. Overall cost: 50000 Swiss francs. The Z4 solved some 100 numerical problems, for example calculations about the world's highest massive dam (Grande Dixence, Swiss Alps) and the Swiss jet fighter P-16. Wolfgang Pauli, Nobel prize laureate in physics, was probably the most famous user of the Z4. In 1951, Heinz Rutishauer independently invented the concept of a language compiler. At that time this method was called automatic programming. He was one of the principal creators of the programming language Algol. The experience gained with the $\mathrm{Z} 4$ facilitated the self-made construction ERMETH. Thanks to the rental of the Z4 by ETH and Remington Rand's order of a series of M9, the Zuse KG was able to survive.

\subsection{ERMETH (Electronic Digital Computer of ETH)}

ERMETH, the first Swiss-made computer, was designed and built from 1953 to 1956 by Eduard Stiefel, Heinz Rutishauser and Ambros Speiser. It was fully operational in 1957 with a magnetic drum (capacity 10000 words). ETH designed a small experimental drum (eventually connected to the Z4 as replacement of the old mechanical memory that was error-prone) and a large definitive drum. Unlike the Z4, the ERMETH was a decimal stored-program computing machine. Rutishauser (a mathematician) and Speiser (an electrical engineer) spent a year of study (1948/1949) in the USA in order to learn the state of the art in computing. They worked at the Harvard University (with Howard Aiken) and the Institute for Advanced Study in Princeton (John von Neumann). Von Neumann had studied chemistry at the ETH. The original budget for the ERMETH (in 1953) was 800000 Swiss francs, the final cost (in 1957) amounted to 1000000 Swiss francs. Swiss industry (Hasler, Gfeller, Wittwer) participated in constructing the ERMETH which was in operation until 1963. At first, ETH thought of a relay computer. As the relays were not reliable enough, they later changed their opinion in favour of vacuum tubes (valves).

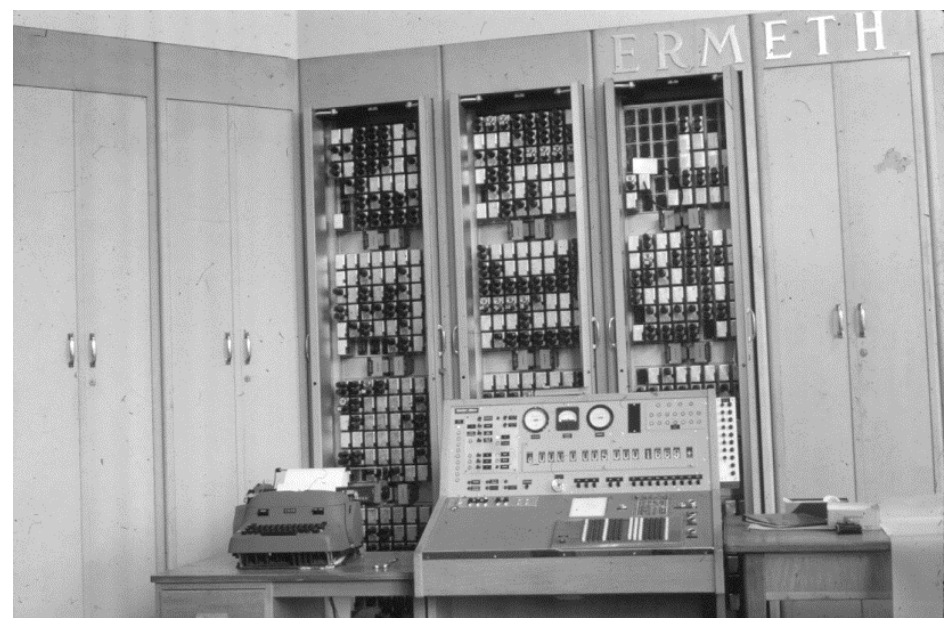

Fig. 7. The first Swiss computer, the stored-program decimal electronic digital ERMETH, ETH Zurich (1956), (C) Museum für Kommunikation, Berne 


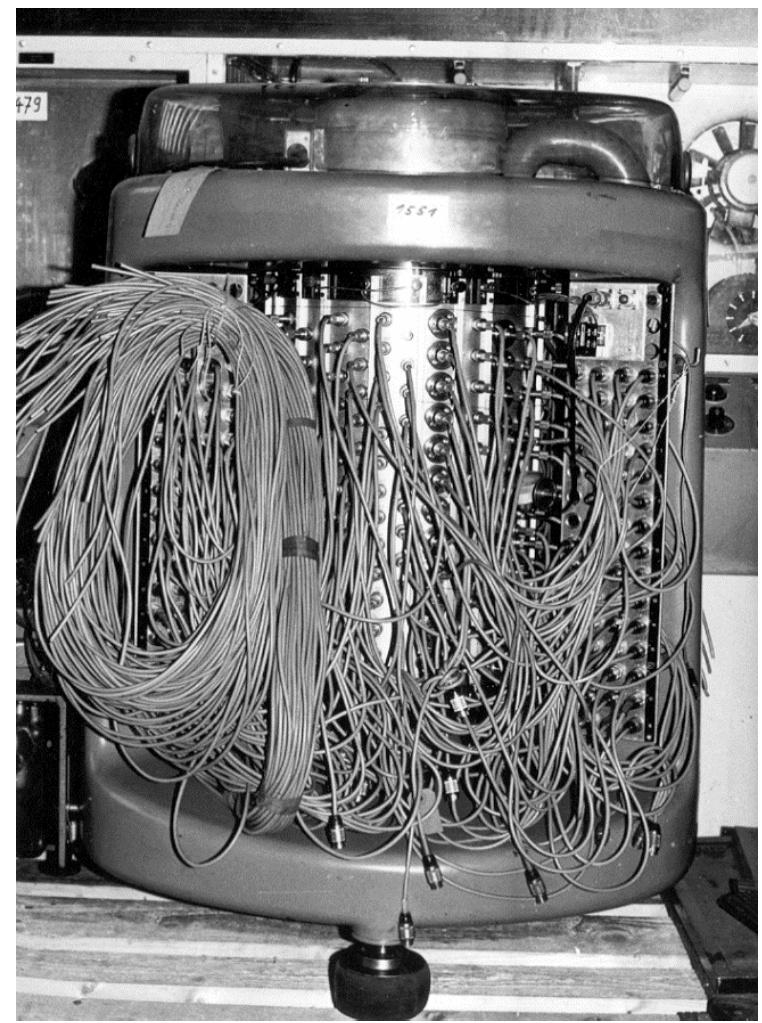

Fig. 8: The Swiss-made magnetic drum of the ERMETH (capacity 10000 words, 80000 bit, 1957), ( ) Museum für Kommunikation, Berne

\subsection{A Selection of the New Documents Found in Switzerland}

- Zuse's intention to flee (sic!) to Switzerland in 1949 with his principal engineers and their families. What was the reason for Zuse's anxiety?

- Several rather complex contracts between Zuse KG and ETH concerning the Z4 (1949). At last, we now know the exact cost of the Z4 (50 000 Swiss francs).

- Howard Aiken's favourable evaluation of the project ERMETH (1952).

- Answer to the question: Why did ETH prefer to design and build ERMETH instead of buying a computer such as Ferranti?

- Documents on the dramatic story of the construction of ERMETH: serious problems with the magnetic drum storage, the M10 disaster (failure of Remington Rand to produce a complex calculating punch), bankruptcy of the provider of the power supply, the insufficient air-conditioning plant from Sulzer, the premature departure of chief engineer Ambros Speiser to IBM at the end of 1955, the permanent shortage of money, etc. All this caused a delay of about two years. 
- The licensing agreement between Hasler AG (now Ascom), Berne, and ETH concerning the magnetic drum of the ERMETH (1955).

- Letters confirming Hasler's intention to commercialize the ERMETH in Europe and USA (1954). This dream seems to have been spoilt by IBM and Speiser respectively.

- The competition arising from new US research laboratories (Battelle, Radio Corporation of America and IBM) challenging Swiss industry and science (headhunting of top scientists thanks to high salaries).

- A research contract between Paillard SA, Yverdon, and ETH regarding the design of a small digital electronic computer (1957-1960).

- Detailed correspondence mainly between Hans Pallmann (president of ETH council) and Eduard Stiefel (founder of the institute of applied mathematics at ETH) related with $\mathrm{Z} 4$ and ERMETH.

- Correspondence between ETH and Remington Rand/Mithra AG. Mithra was a subsidiary of Remington Rand (Switzerland), but was later directly governed by Remington Rand (USA). Mithra encountered insurmountable technical difficulties during the construction of M10 (successor to M9). ETH had ordered two machines. After a delay of three years they suddenly gave it up. Because of the problems, Presper Eckert, chief engineer of ENIAC, came to Zurich. In the end, the M10 was replaced by two Univac 120 machines. By the way, John Mauchly and Presper Eckert had Swiss ancestors.

- Establishment of an international computer laboratory by Unesco in Europe. In 1951, the University of Zurich and the Swiss Federal Institute of Technology (ETH) had applied for this center but later they cancelled the offer. In the end, the laboratory was established in Rome.

\section{$4 \quad$ Additions}

- Mysterious meeting between the computer pioneers Alan Turing and Konrad Zuse. Did Konrad Zuse meet Alan Turing in Göttingen in 1947? The German inventor Heinz Billing mentions an interrogation by British computer scientists in his memoirs. Unfortunately we did not find any further proofs.

- Paul Bernays enforces a correction of Turing's paper "On computable numbers". In 1936, Paul Bernays, a mathematician at ETH, detects some errors in Turing's famous paper. Turing therefore published a correction in 1937.

- Later Swiss inventions. Other significant Swiss achievements were the innovative work stations Lilith (1978, sold as Diser) and Ceres (1986) as well as influential programming languages like Pascal (1970), Modula, Oberon (by Turing award winner Niklaus Wirth and Jürg Gutknecht).

- Falsification. I received three detailed alleged eyewitness reports on Alan Turing, Contraves AG and Paillard SA. They were provided by the same author. The falsified adventurous paper on Turing is a product of fantasy, the text on Contraves is at least partially falsified. The articles on Contraves and Paillard have been published in a shortened version in "Ingenieure bauen die Schweiz" (NZZ publishers, Zurich 2013). 


\section{Conclusions}

The history on the invention of the computer is full of controversy and often rather patriotic, biased or plainly wrong. Three nations - USA, England and Germany claim to have invented the computer. Who is right? The answer is quite simple: The computer was independently born in these three countries. The actual response depends on the definition of the computer.

The archives of ETH Zurich are a very precious place for further research into the early history of computing. The newly found documents prove that the ETH president Hans Pallmann played a decisive role in renting the German Zuse relay computer Z4 and in building the Swiss electronic digital computer ERMETH. There are still many open questions: Where are the archives of Zuse KG? Who told Stiefel about the Z4? And we still miss the experimental magnetic drum fabricated by ETH and sold to Zuse. Did Contraves design another computer (C2000)?

The Z4 and the M9 (=Z9) are the only two early Zuse devices which were conserved. The original Z4 is exhibited at the Deutsches Museum, Munich. The M9 and the ERMETH are to be found at the Museum für Kommunikation in Berne.

Acknowledgements. The author is very thankful for the help of the ETH archives' staff.

\section{References}

1. Protocols of the ETH council, http: / / www.sr. ethbib. ethz.ch/digbib/home

2. Bruderer, H.: Konrad Zuse und die Schweiz. Wer hat den Computer erfunden (Konrad Zuse and Switzerland. Who invented the computer?), $250 \mathrm{p}$. Oldenbourg-Wissenschaftsverlag, Munich (2012) (with eyewitness reports and a worldwide bibliography of over 500 publications)

3. Bruderer, H.: Wer hat den Computer erfunden? Frühgeschichte der Informatik: USA, England, Deutschland, Österreich, Schweiz. Mit mehreren Zeitzeugenberichten. Bibliografie zur Informatikgeschichte mit über 1200 Einträgen, Munich/Berlin (2014) (Who invented the computer? Early history of computing: USA, England, Germany, Austria, Switzerland. With several eyewitness reports. Bibliography on the history of computing with over 1200 publications) 